E Q U I L I B R I U M

Volume 6 IsSue 1, 2011

IS S N $1689-765 \mathrm{X}$

\author{
Julia Włodarczyk \\ University of Economics in Katowice, Poland
}

\title{
Comparative Analysis of the Course of Business Cycles and Thermodynamic Cycles
}

\section{JEL Classification Codes: E32}

Keywords: business cycles, thermodynamic cycles, expansion, contraction, efficiency

\begin{abstract}
Mainstream economics tends to perceive economic systems in a mechanistic way, which makes it impossible to grasp the notion of the irreversibility of real economic processes and thus encourages referring to the achievements of thermodynamics.Although economic equivalents of thermodynamic quantities have been discussed for more than a hundred years, a significant development of thermodynamic techniques of modeling economic phenomena, that could complement standard econometric methods, has not been observed.It seems that a comparative analysis of the course of thermodynamic and business cycles could enhance the understanding of the mechanisms underlying business cycles, especially in the context of mutual relations between economy and its environment.The aim of this article is to discuss some similarities and differences between economic and thermodynamic systems (heat engines and heat pumps). In particular, the problem of performing positive or negative work by an economy is considered and illustrated by the analysis of statistical data referring to the American and Polish economies.
\end{abstract}

\section{Introduction}

Mainstream economics tends to perceive economic systems in a mechanistic way (e.g. fluctuations of prices and volume of production during the business cycle are often compared to the motion of a pendulum in a clock mechanism). Such an approach makes it impossible to grasp the notion of the irreversibility of real economic processes and encourages referring to the achievements of thermodynamics, which is the only discipline taking irreversibility for granted. So, from the methodological point of view, conducted considerations are justified by the propositions of the general systems theory to some extent. 
Although economic equivalents of thermodynamic quantities have been discussed for more than a hundred years ${ }^{1}$, a significant development of thermodynamic techniques of modeling economic phenomena, which could complement standard econometric methods, has not been observed. Irrespective of any controversies resulting from the comparison of thermodynamic and economic systems, it seems that recognizing similarities between business cycles and thermodynamic cycles would allow defining new indexes of economic efficiency.

Such a comparative analysis could also enhance the understanding of the mechanisms underlying business cycles, especially in the context of mutual relations between economy and its environment.

The aim of this article is to discuss some similarities and differences between economic and thermodynamic systems (such as heat engines or heat pumps). In particular, the problem of performing positive or negative work by an economy is considered and illustrated by the analysis of statistical data referring to the American and Polish economies.

The first section of this paper discusses some aspects of the problem of irreversibility in thermodynamics and economics. The second section provides an economic interpretation of thermodynamic cycles. The third section presents some empirical findings on business cycles and the final section concludes.

\section{Thermodynamics, economics and irreversibility}

Basing reflections on the analogy between economic and thermodynamic systems is reasonable, since even the representatives of mainstream economics have noticed that the relations between volume and pressure in thermodynamic systems correspond with the relations between output volume and prices in economic systems (Samuelson 1972, pp. 254-255)2.

${ }^{1}$ It is worth emphasizing that among other contributions an attempt to connect economic and energetic categories was also undertaken in Poland (Heryng 1896). Nevertheless, at that time the economists did not succeed in explaining real economic phenomena through the idea of energy transformation. To some extent this inability was caused by disregarding the second law of thermodynamics (Włodarczyk 2008).

${ }^{2}$ Generally, Samuelson (1972, p. 254) firmly criticized forcing analogies between economic and physical concepts (especially the concept of entropy or the application of the Heisenberg principle of indeterminacy in the socio-economic system). Nevertheless, he proposed the application of Le Chatelier principle in economics. Accordingly, prices and quantities of inputs (or output volume) are in a dualistic relation: for example, when the price of input increases, the quantity or the price of the second input can be held constant. In the former case long-term adjustment will be less elastic than in the latter (Samuelson 1972, p. 255). This observation is consistent with the discrepancies between the shape of market demand curve (less elastic) and company's demand curve (more elastic). 
Besides, the equation of quantity theory of money precisely projects the ideal gas equation (Szargut 2000, pp. 70-71; Bryant 2007, pp. 302-337):

$$
P V=N k T
$$

where $P$ stands for pressure in thermodynamics or unit price in economics, $V$ - gas volume or output volume respectively, $N$ - amount of substance or the number of monetary units, $k$ - Boltzmann constant or a constant defining the nominal value of a monetary unit $(1 \$, 1 €$ etc.), $T$ - temperature or value trading index. Money supply can be calculated as $N k$ and total turnover as $N k T$. Although in the analysis of monetary phenomena $T$ becomes circulation velocity of money, the above mentioned equation can be also referred to the processes on the capital market, production and consumption (Bryant 2009, pp. 6-10).

The problem of irreversibility in thermodynamic and economic systems can be illustrated with a following example: if the total turnover $(N k T)$ is held constant, the thermodynamic process reduces to the isothermal process $(P V=$ constant, but both $P$ and $V$ can change inversely proportional to each other). In the economic interpretation the product of price and output volume would be constant. So any changes of prices or quantities can be illustrated unit elastic demand curves (presented in figure 1a) as $T_{1}$ or $T_{2}$ ). Moving along these curves is reversible.

However, in thermodynamic as well as in economic interpretation (for instance, due to dissipation of energy or effect of speculation) there is a possibility that real processes would be irreversible and less efficient than could be expected (which is presented in figure 1b), where B is an ideal case and B' the real one).

All natural as well as economic processes are irreversible. From the thermodynamic point of view, the irreversibility of processes does not preclude the system from returning to its initial state. It is impossible for the environment of that system to return to its initial conditions, though.

Therefore, the economic interpretation of irreversibility should not be limited to the sunk costs borne by companies within the process of investment or production. Of course, both production and consumption of bread are irreversible. However, to a certain extent reversibility can be achieved during a business cycle when energy from consumption of bread makes it possible to produce another loaf of bread (Bryant 2009, p. 50). This simplification also underlies the construction of the model of circular flow in the economy.

To conclude, it is worth reminding that according to the second law of thermodynamics it is not possible to construct a system operating cyclically, so the descriptions of both thermodynamic cycles and business cycles are to some extent an idealization. Therefore, the thermodynamic analysis of business cycles requires elimination of economic growth trend.

\footnotetext{
${ }^{3}$ More precisely, pressure in physics is symbolized with $p$ (not with $P$ ).
} 
Figure 1. Reversible and irreversible thermodynamic and economic processes

a) reversible process

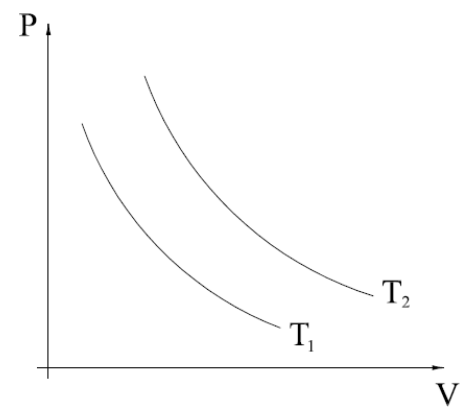

b) irreversible process

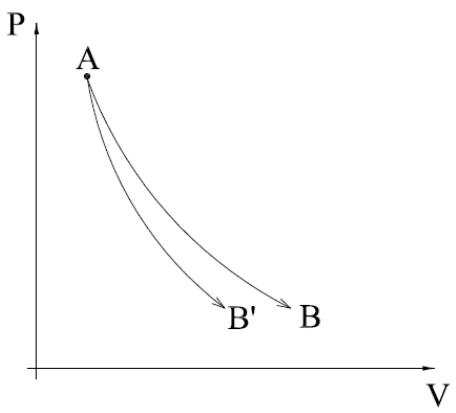

Source: Author's elaboration based on Bryant (2009, p. 47-49).

\section{Thermodynamic processes and their economic interpretation}

Thermodynamic cycle consists of such thermodynamic processes that enable the system to return to its initial state, so it can be presented as a closed curve (in this paper only relations between volume and pressure are analyzed, but this observation refers to other relations as well).

The analysis of heat engines in which gas is the working substance demonstrates that the thermodynamic cycle can be divided into the process of decompression or expansion of a gas (in this situation gas gives back energy through performing work) and the process of compression or contraction of a gas (in this case work is performed on the gas by external forces and the gas absorbs heat). In the power cycle a gas performs positive work - graphically, it runs around a closed curve in a clockwise motion and the area limited by this curve is equal to the amount of work being done (figure 2). In the inverse cycle, which is represented graphically by a closed curve being run around by the gas in an anticlockwise motion, the system performs negative work, because the gas absorbs heat from the body characterized by lower temperature and gives it back to the body with a higher temperature at the expense of work done on the gas (Szargut 2000, pp. 118-119).

As it was stated in the previous section, it is the quantity theory of money that links the heterogeneous economic output with thermodynamic categories. All forms of output are expressed in monetary terms, prices are reflected by deflator and temperature by the velocity of circulation (Bryant 2009, p. 162).

Therefore, at least theoretically, the course of business cycle can be interpreted analogically as the course of thermodynamic cycles. The functioning of an economy resembles the operation of heat engines or heat pumps, because each 
economy is subject to the processes of expansion and contraction. The working substance may consist of monetary units. In an economy (just as in the heat engine) the existence of different levels of economic equivalents of temperature allows the economic agents to acquire profits until the levels of thermodynamic potentials (e.g. prices or other intensive variables) become even (Drăgulescu, Yakovenko 2000, p. 725). In this context, it is also worth noticing that so far, totally stable or unstable (chaotic) price movements do not allow to acquire profits; meanwhile, sinusoidal price movements (depending on their frequency and amplitude) make it possible to accumulate profits (Perison 2001).

Figure 2. Work performed by the gas in the thermodynamic power cycle and its economic interpretation

symbols:

$\mathrm{P}$ - pressure or price

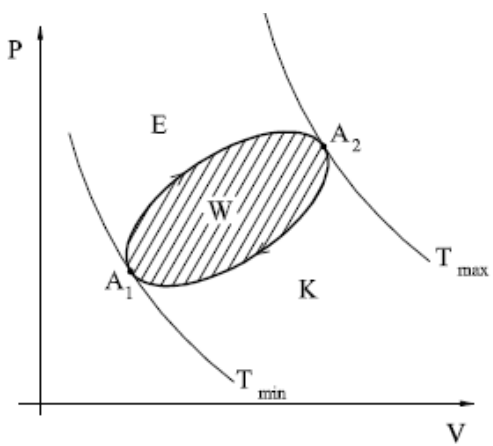

$\mathrm{V}$ - gas volume or output volume

E - expansion, decompression (performing work by the working substance) or economic expansion

$\mathrm{K}$ - compression, contraction (performing work by the external forces) or economic recession $\mathrm{A}_{1}$ - absorbing heat by the gas or the lower turning point in the business cycle

$\mathrm{A}_{2}$ - giving back heat by the gas or the higher turning point in the business cycle $\mathrm{W}$ - work being done by the thermodynamic or economic system

Source: Author's elaboration based on Szargut (2000, p. 118).

It is essential to determine whether an economy is operating in a power or inverse cycle - in other words, if it produces work (that is a positive real output) or heat (values that do not yield any real benefits). Besides, one should analyze the possible character of thermodynamic or economic processes, which allow to construct cycles with a different degree of thermal efficiency, which can be calculated as the proportion of work performed by the working substance to the total heat delivered to the system. Typical processes that could have both a thermodynamic and economic interpretation are graphically presented in figure 3. 
Figure 3. Thermodynamic and economic processes in a theoretical approach

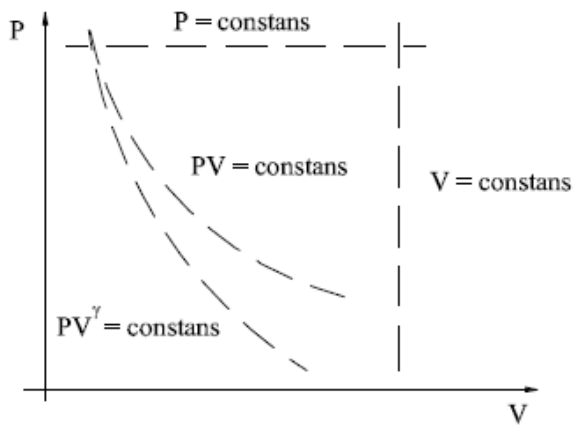

Source: Bryant (2009, p. 58).

The processes presented in figure 3 are described in more detail in table 1.

Table 1. Characteristic (reversible) thermodynamic processes of ideal gases in closed systems and their economic interpretation

\begin{tabular}{|c|c|c|}
\hline Processes & Thermodynamic interpretation & Economic interpretation \\
\hline $\begin{array}{l}P V=\text { constans } \\
\left(\frac{P_{2}}{P_{1}}=\frac{V_{1}}{V_{2}}\right)\end{array}$ & $\begin{array}{l}\text { isothermal process - absolute } \\
\text { work done during the process } \\
\text { is equal to the amount of heat } \\
\text { absorbed by the gas }(d W=d Q) \text {, } \\
\text { it is the most efficient process, } \\
\text { however it is difficult to be } \\
\text { achieved }\end{array}$ & $\begin{array}{l}\text { process during which the total } \\
\text { amount of expenditures or } \\
\text { turnovers (or the circulation } \\
\text { velocity of money) is constant - } \\
\text { it resembles movement along } \\
\text { a unit elastic curve of demand }\end{array}$ \\
\hline $\begin{array}{l}V=\text { constans } \\
\left(\frac{P_{2}}{P_{1}}=\frac{T_{2}}{T_{1}}\right)\end{array}$ & $\begin{array}{l}\text { isochoric process }- \text { absolute work } \\
\text { done during the process is equal to } \\
\text { zero }(d W=0)\end{array}$ & $\begin{array}{l}\text { process during which the total } \\
\text { output volume is constant - it } \\
\text { resembles movement along } \\
\text { a perfectly inelastic curve of } \\
\text { supply (or demand) }\end{array}$ \\
\hline $\begin{array}{l}P=\text { constans } \\
\left(\frac{V_{2}}{V_{1}}=\frac{T_{2}}{T_{1}}\right)\end{array}$ & $\begin{array}{l}\text { isobaric process - absolute } \\
\text { work done during the process is } \\
\text { proportional to the increase of } \\
\text { volume }\left(d W=P\left(V_{2}-V_{1}\right)\right)\end{array}$ & $\begin{array}{l}\text { process during which the price } \\
\text { level is constant - it resembles } \\
\text { movement along a perfectly } \\
\text { elastic curve of supply (or } \\
\text { demand) }\end{array}$ \\
\hline $\begin{array}{l}P V^{m}=\text { constans } \\
\left(\frac{P_{1}}{P_{2}}=\left(\frac{V_{2}}{V_{1}}\right)^{m}\right)\end{array}$ & $\begin{array}{l}\text { politropic process* } * \text { absolute } \\
\text { work done during the process } \\
\text { is equal to the decrease of the } \\
\text { internal energy of the gas }(d W= \\
-d U),\end{array}$ & $\begin{array}{l}\text { process during which the total } \\
\text { amount of expenditures or } \\
\text { turnovers (or the circulation } \\
\text { velocity of money) is changing } \\
\text { proportionately - it resembles } \\
\text { movement along an isoelastic } \\
\text { curve of demand }\end{array}$ \\
\hline
\end{tabular}

* A special case of politropic process is an isentropic process (reversible adiabatic process), which occurs when $\left(m=\frac{c_{p}}{c_{v}}\right)$, where $c_{p}$ stands for heat capacity at constant pressure and $c_{v}$ for heat capacity at constant volume.

Source: Author's elaboration based on Szargut (2000, p. 92-108). 
In accordance with the description included in table 1, it is worth emphasizing that the economic interpretation of isochoric and isobaric process is consistent with the Keynesian propositions on the shape of the curve of aggregated supply. In the first case, an increase of aggregated demand leads to the increase in production while the general price level remains unchanged, but in the second, situation an increase of aggregated demand leads to the increase of the general price level while the volume of production cannot exceed the level of potential production and hence does not change.

In the economic literature there are not many theoretical examples referring to the thermodynamic cycles (figure 4 and table 2), despite the fact that, as was mentioned above, the quantity theory of money allows to compare an economy to a cyclic thermodynamic system.

Figure 4. Joule's cycle

Source: Bryant (2009, p. 162).

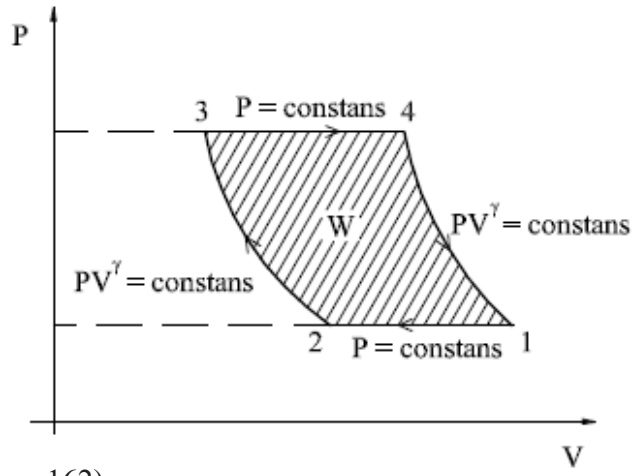

Table 2. Joule's cycle in the microeconomic interpretation

\begin{tabular}{|c|c|c|}
\hline Process & $\begin{array}{c}\text { Interpretation for } \\
\text { companies }\end{array}$ & Interpretation for households \\
\hline $\begin{array}{c}1-2(\mathrm{P}=\text { constans }) \\
\text { isobaric compression }\end{array}$ & $\begin{array}{c}\text { inflow of factors of production } \\
\text { and outflow of factor income }\end{array}$ & $\begin{array}{c}\text { inflow of goods and outflow of } \\
\text { consumption expenditures }\end{array}$ \\
\hline $\begin{array}{c}2-3(\mathrm{~S}=\text { constans }) \\
\text { adiabatic compression }\end{array}$ & $\begin{array}{c}\text { consumption, depreciation of } \\
\text { capital }\end{array}$ & consumption, working \\
\hline $\begin{array}{c}3-4(\mathrm{P}=\text { constans }) \\
\text { isobaric expansion }\end{array}$ & $\begin{array}{c}\text { outflow of produced goods } \\
\text { and inflow of revenues }\end{array}$ & $\begin{array}{c}\text { outflow of results of working and } \\
\text { inflow of wages and salaries }\end{array}$ \\
\hline $\begin{array}{c}4-1(\mathrm{~S}=\text { constans }) \\
\text { adiabatic expansion }\end{array}$ & gain or loss & reproduction of labour force \\
\hline
\end{tabular}

Source: Author's elaboration based on Bryant (2007, p. 22).

The interpretation proposed in figure 4 and table 2 can be supplemented by additional costs (for instance related with the protection of the environment in 
process 1-2 or with taxation of economic agents in process 4-1) (Bryant 2007, pp. 22). Nevertheless, one can formulate several stipulations directed at the proposition presented above.

Firstly, the interpretation of a business cycle as a closed cycle would imply that entropy does not increase which is improbable in the economic reality (Bryant 2007, p. 30).

Secondly, such an interpretation has only microeconomic character. However, there is a possibility to formulate a macroeconomic interpretation according to which business cycle would consist of four processes related with consumption expenditures, depreciation of capital, gross production and reinvestment of gains (Bryant 2009, p. 163).

Thirdly, it is quite controversial that process $1-2$ for companies mirrors process 3-4 for households (and inversely, process 34 for companies reflects process 1-2 for households). In other words, it is peculiar that according to the content of table 2 households would buy goods and services at low prices and they would receive wages and salaries at high prices. Such a situation is unrealistic, because the economic activity of companies would be unprofitable.

Finally, it seems implausible that the similarities between thermodynamic and economic systems could be so far-reaching that the economy would operate precisely according to characteristic thermodynamic constructions.

\section{Empirical analysis of business cycles}

In accordance with conducted considerations, it is worth analyzing the course of real business cycles. American business cycles (which are presented in chart 5) are dated from peak to peak on the basis of the announcements of the National Bureau of Economic Research (2011). Long-term prices and GDP growth trends have been eliminated.

Figure 5. Business cycles in United States of America in the years 1937-2007

a) $1937-1944$

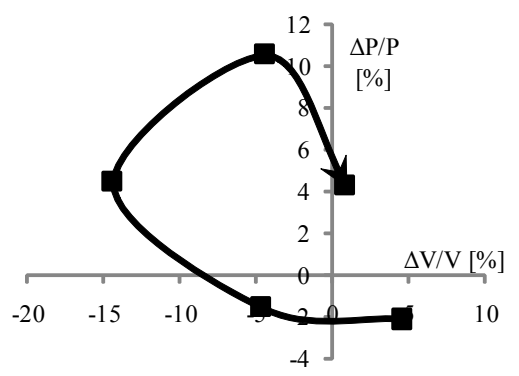

b) $1944-1948$

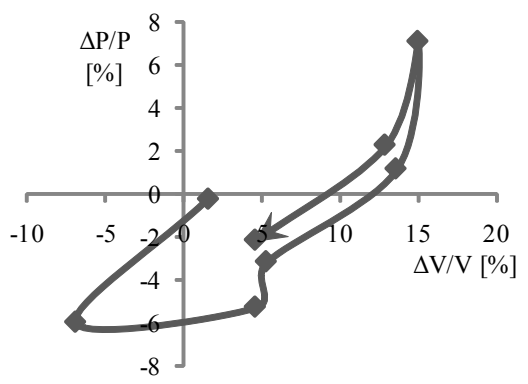


c) $1948-1953$

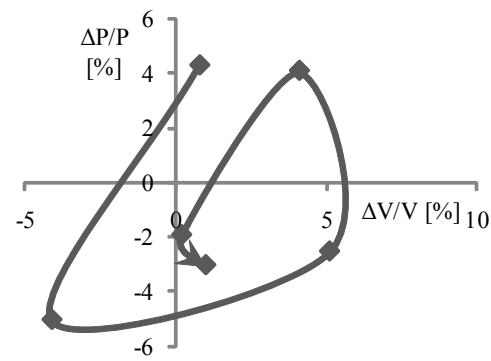

e) $1957-1960$

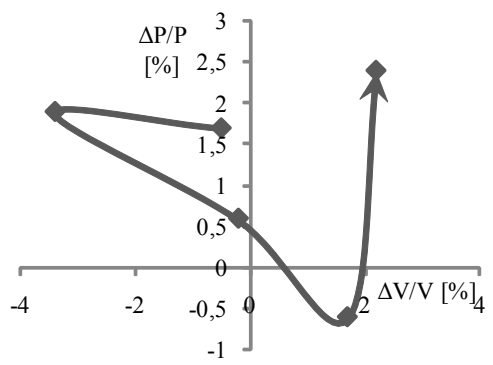

g) 1969-1973

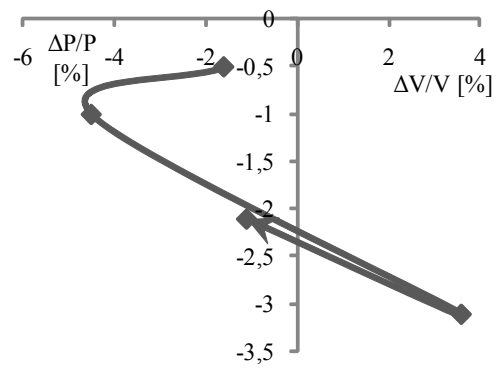

d) $1953-1957$

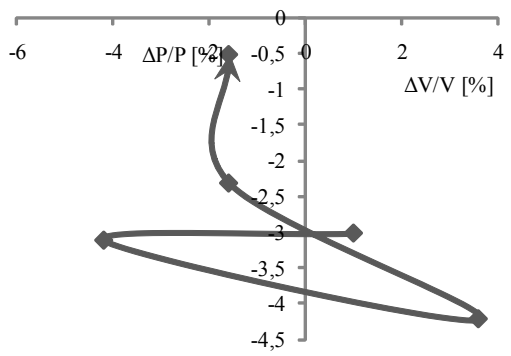

f) 1960-1969

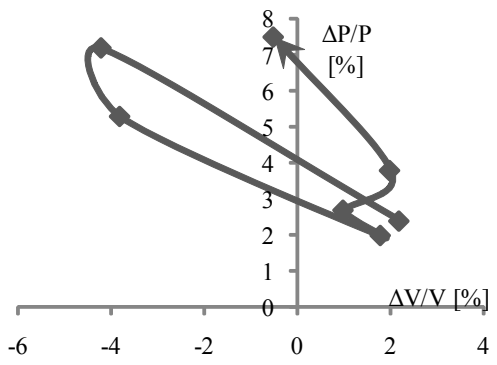

h) 1973-1979

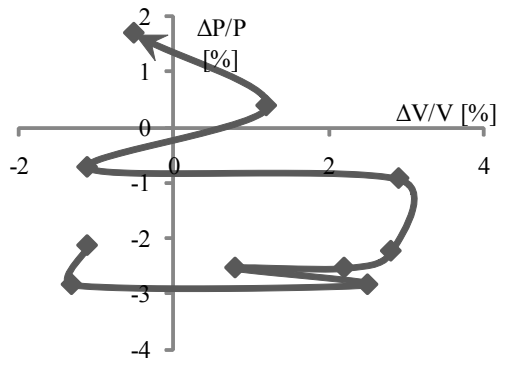


i) $1979-1981$

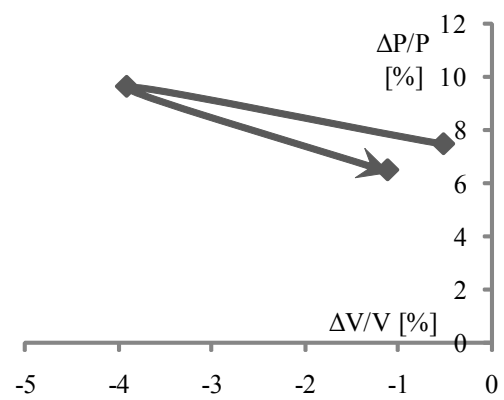

k) $1990-2000$

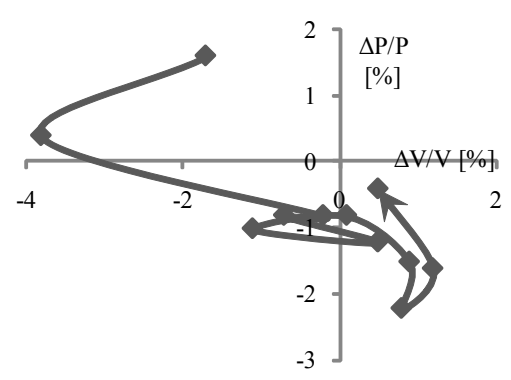

j) $1981-1990$

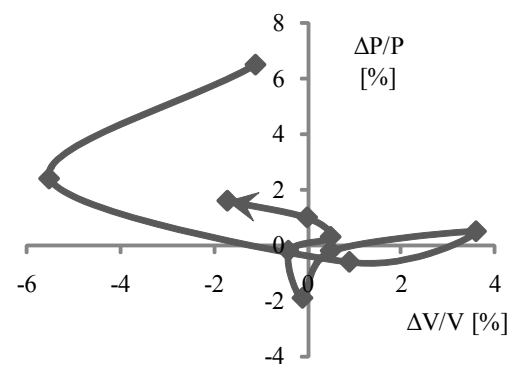

1) $2000-2007$

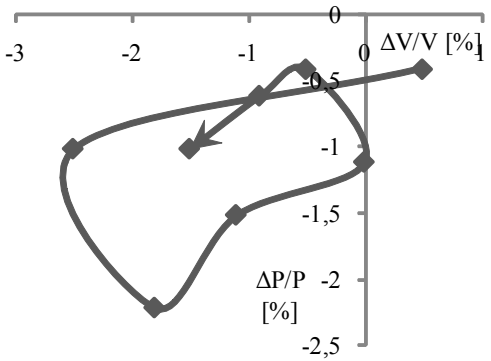

Source: author's elaboration based on the data from the Bureau of Economic Analysis (2011) and the Bureau of Labor Statistics (2011).

In most cases presented in figure 5 even the elimination of the long-term growth trends does not allow to obtain closed cycles. It is also difficult to assign observed fluctuations to specific types of thermodynamic processes.

Nevertheless, one can state that (with the exception of the cycle dated for the years 1944-1948 when the American economy functioned in the power cycle) processes observed in the whole analyzed period generally resemble the inverse (anticlockwise) thermodynamic cycle. This means that the American economy functions similarly to the heat pump which performs negative work and (at the expense of external forces) contributes to extending differences between levels of temperature. In this interpretation American economy would be responsible for increasing inequalities in the socio-economic system.

However, the unreality of construction of an unambiguous model of business cycles in American economy makes it also impossible to calculate a coefficient of performance for this specific heat pump (such a coefficient is inversely proportional to the efficiency of systems functioning in the power cycle). 
Besides, without further analyses it cannot be determined whether the American economy grows at the expense of its economic surroundings (i.e. other countries) or its extraeconomic surroundings (e.g. natural environment).

Therefore, it is advisable to compare American cycles with data from another country. Figure 6 presents business cycles in Poland ${ }^{4}$.

Figure 6. Business cycles in Poland in the years 1991-2007

a) $1991-2000$

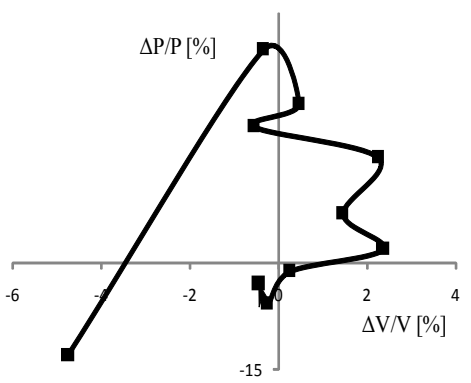

b) 2000-2007

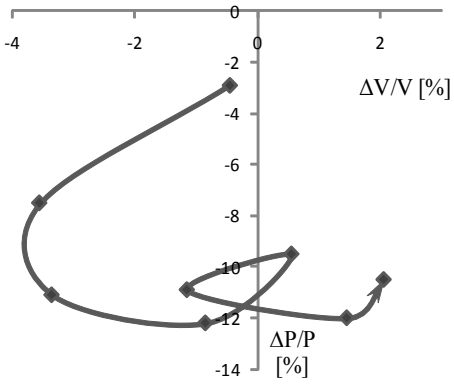

Source: Author's elaboration based on the data from Central Statistical Office in Poland (GUS 2011).

After transformation one could observe a power cycle in Poland (just like in the United States of America in the post-war period). However, in the following years fluctuations changed into the inverse cycle.

Despite all stipulations, it seems that referring to the achievements of thermodynamics (especially the theory of thermal machines) is an interesting proposition allowing to perceive the efficiency of economic processes in different categories.

\section{Conclusions}

Thermodynamics and the theory of thermal machines in particular cannot be treated as an ultimate source of explanation of the mechanisms of business cycles. However, this reference seems to be indispensable in such a sense that it helps to bring together traditional (mechanistic) interpretations of business cycles and potentially new propositions taking into account irreversibility, heterogeneity and other qualitative aspects of economic phenomena (table 3).

${ }^{4}$ Actually, for the purpose of comparison, the data is organized just like in the figure 5k and 1). The only exception is the omission of the observations for the year 1990, because of extreme values of both variables resulting from the process of systemic transformation in Poland. 
Table 3. Levels of interpretation of the mechanisms of business cycles

\begin{tabular}{|c|c|}
\hline $\begin{array}{c}\text { Mechanics } \\
\text { (reversibility, } \\
\text { homogeneity) }\end{array}$ & $\begin{array}{r}\text { traditional (mechanistic) interpretations of business cycles - } \\
\text { fluctuations of prices and volume of production during the business } \\
\text { cycle are compared to the motion of a pendulum in a clock } \\
\text { mechanism }\end{array}$ \\
\hline $\begin{array}{c}\text { Thermodynamics } \\
\text { (irreversibility, } \\
\text { homogeneity) }\end{array}$ & $\begin{array}{r}\text { thermodynamic interpretations of business cycles - fluctuations } \\
\text { of prices and volume of production during the business cycle are } \\
\text { compared to the motion of a piston in a cylinder }\end{array}$ \\
\hline$?$ \\
$\begin{array}{c}\text { (irreversibility, } \\
\text { heterogeneity) }\end{array}$ & $\begin{array}{r}\text { desirable interpretations of business cycles - fluctuations of prices } \\
\text { and volume of production during the business cycle are explained in } \\
\text { terms of complexity of socio-economic systems }\end{array}$ \\
\hline
\end{tabular}

Source: author's elaboration.

The thermodynamic interpretation of business cycles allows to put forward a hypothesis that business cycles can be divided into:

- productive cycles - characterized by a clockwise motion of economic variables presented on the P-V diagram,

- unproductive cycles - characterized by an anticlockwise motion.

It could be interesting to analyze the conditions that determine the occurrence of each type of cycle (including fiscal and monetary policy stance) as well as estimate appropriate coefficients of efficiency or performance of an economic system. Nevertheless, this division is not made upon economic but thermodynamic criterion. This means that and unproductive cycle could be profitable for an economy which is able to take over resources from its environment.

It is also worth noticing that, in fact, most reservations concerning the analogies between thermodynamic and business cycles apply to the quantity theory of money (which constitutes foundations of conducted considerations) as well. Therefore, further research could investigate whether the asymmetrical relations between work and heat during thermodynamic processes can be related to the level of concentration or dispersion of money among the economic agents.

To recapitulate, controversial as this may seem, the comparative analysis of thermodynamic and business cycles promotes analyzing business cycles in a broader perspective and interdisciplinary research in general. Furthermore, empirical investigations presented in this paper have shown that not only unemployment rates but also other economic variables may exhibit hysteresis. Obviously, this preliminary observation requires further research. 


\section{Literature}

Bryant J. (2007), A Thermodynamic Theory of Economics, http://www.vocat.co.uk/TEFPRV 2007.pdf (as of 15.03.2011).

Bryant J. (2009), Thermoeconomics. A Thermodynamic Approach to Economics, VOCAT International, Harpenden.

Bureau of Economic Analysis (2011), http://www.bea.gov (as of 15.03.2011).

Bureau of Labor Statistics (2011), http://www.bls.gov (as of 15.03.2011).

Central Statistical Office in Poland (GUS 2011), http://www.stat.gov.pl (as of 15.03.2011).

Drăgulescu A., Yakovenko V.M. (2000), Statistical mechanics of money, „European Physical Journal B", vol. 17.

Heryng Z. (1896), Logika ekonomii. Zasadnicze pojęcia ekonomiczne ze stanowiska nauki o energii, Wyd. „Głosu”, Warszawa.

National Bureau of Economic Research (2011), http://www.nber.org (as of 15.03.2011).

Perison A.G. (2001), Uncertainty, Indeterminacy and Shannon's Derivation of Entropy: Implications for Policy Administration - A Systems Theoretical Approach, Working Paper, http://ideas.repec.org/p/wpa/wuwpma/0112001.html (as of 15.03.2011).

Samuelson P. (1972), Maximum Principles in Analytical Economics, "The American Economic Review", Vol. 62.

Szargut J. (2000), Termodynamika, PWN, Warszawa.

Włodarczyk J. (2008), Ekonomia jako nauka o energii społecznej w polskiej myśli ekonomicznej przełomu XIX i XX wieku, [in:] Zagóra-Jonszta U. (ed.), Zagadnienia ekonomiczne w ujęciu historycznym oraz teorii i polityki gospodarczej, Studia Ekonomiczne nr 54, Wyd. Uczelniane Akademii Ekonomicznej w Katowicach, Katowice. 
